\title{
Effects of isolation rearing on keypecking in young domestic chicks
}

\author{
JAMES F. ZOLMAN, JOYCE A. HALL, and CHRISTIE L. SAHLEY \\ Physiology and Biophysics, Medical Center, University of Kentucky, Lexington, Kentucky 40506
}

Forty-eight Vantress $\times$ Arbor Acre chicks were reared either in groups of 12 or individually until 3 days old and then trained individually in an autoshaping keypecking situation using heat reinforcement. Following six training sessions of 24 trials each, all chicks were given two extinction sessions of 24 trials each. Major findings were as follows: (1) The isolation-reared chicks made significantly more responses with shorter latencies during training than did the social-reared chicks; (2) the isolation-reared chicks extinguished more slowly than did the socialreared chicks, reflecting mainly the terminal acquisition differences between the two rearing groups.

Isolation rearing of young domestic chicks has been found to affect the total amount of following of surrogate stimuli in imprinting studies, choice behavior in discrimination testing, and response suppression in passive avoidance learning. As examples, isolation-reared chicks follow surrogate objects more than do social-reared chicks of the same age (Guiton, 1959; Sluckin \& Salzen, 1961; Smith \& Bird, 1963). In discrimination learning, isolation-reared chicks make more correct responses than social-reared chicks when required to approach a goalbox containing a stimulus and to avoid an empty goalbox (Zolman, 1968). In contrast, isolation-reared chicks are inferior passive avoidance learners compared to social-reared chicks (Brown, 1976).

Apparently, isolation rearing, among other effects, leads to less inhibition and greater activity and responsiveness in young domestic chicks. The purpose of the present study, therefore, was to determine whether isolation rearing affects the young chick's acquisition and extinction of a keypeck response using an autoshaping procedure.

\section{METHOD}

\section{Subjects and Experimental Design}

Forty-eight Vantress X Arbor Acre chicks were incubated and hatched at $37^{\circ} \mathrm{C}-38^{\circ} \mathrm{C}$ and $56 \%-60 \%$ relative humidity from six hatches spaced over a 3-week period. Each chick was removed from the dark hatching incubator and banded within $4 \mathrm{~h}$ after hatching. Chicks from each hatch were randomly assigned to four groups in a complete 2 (rearing) by 2 (stimulus) factorial design with 12 chicks in each group.

This work was supported by Grant MH 24260 from the National Institute of Mental Health and by the Human Developmental Studies Program of the College of Medicine, University of Kentucky, with funds granted by the Foundations' Fund for Research in Psychiatry (T64-205). The authors are grateful to S. Curtis, K. Martynowicz, and P. Murphy for their assistance during behavioral testing, and to D. McFarland for his assistance in data reduction and analysis.
One half of the chicks were reared socially in groups of 12 in white Plexiglas communal brooders $(56 \times 33 \times 23 \mathrm{~cm})$ and the other 24 chicks were reared individually in white Plexiglas cylinders $(20 \times 15 \mathrm{~cm})$. Extra age-matched chicks were used every week to maintain the social-rearing condition at 12 chicks. The brooder room was maintained at $35^{\circ} \mathrm{C}$ and was illuminated with fluorescent light from 6:00 a.m. until 11:00 p.m. All chicks were deprived of food and water during rearing and began testing when 3 days old $(74.3 \mathrm{~h}, \mathrm{SD}=2.9)$.

\section{Apparatus}

Behavioral testing was performed in four conditioning boxes designed for keypeck conditioning of young chicks using heat reinforcement. The boxes have been described previously (Zolman, Chandler, \& Black, 1972; Zolman, Pursley, Hall, \& Sahley, 1975). IEE 12-unit inline projectors were used to present the stimuli on a single transparent key. The key was $4 \mathrm{~cm}$ from the floor and tilted away from the chick at a 135-deg angle from the plane of the hardware cloth floor. Each conditioning chamber was housed individually in a Forma Scientific incubator (Model 3665) in which the ambient temperature was set at $10^{\circ} \mathrm{C}\left( \pm 1^{\circ} \mathrm{C}\right)$. Another Forma Scientific incubator with an auxiliary $2,000-\mathrm{W}$ heater was set at $38^{\circ} \mathrm{C}$, and plastic tubing $(20$ and $10 \mathrm{~cm})$ connected each cold incubator with this heat source. A push-pull fan arrangement in the heat incubator was used to maintain a balanced flow of warm air to each conditioning incubator. The air temperature under each conditioning box was maintained at $35^{\circ} \mathrm{C}$ and was monitored continuously by a Yellow Springs air telethermometer. The ambient temperature on the wire floor of each conditioning box was maintained at $10^{\circ} \mathrm{C}$ and was also monitored continuously. Heat onset in each conditioning box was controlled by two separate Ledex rotary solenoids that when activated displaced two $10-\mathrm{cm}$-diam circular butterfly valves. One valve diverted instantaneously the warm $35^{\circ} \mathrm{C}$ air up through the conditioning box, whereas the other valve opened to replace in the air flow system the same amount of warm air diverted. Thus, air flow in this system was balanced so that reinforcement delivered in any of the conditioning boxes did not affect the flow of warm air to the other boxes (cf. Zolman et al., 1975). A 2-W light bulb located under each conditioning box was also turned on so that reinforcement consisted of both heat and light onset. A small Rotron whisper fan located $25 \mathrm{~cm}$ above the open top of the conditioning box was turned on immediately after reinforcement and remained on during the intertrial interval. This fan dispersed any residual heat remaining in the box after reinforcement. 
A white masking noise of $76 \mathrm{~dB}$ re $20 \mathrm{microN} / \mathrm{m}^{2}$ was delivered through a $10-\mathrm{cm}$ speaker on the back wall of each testing incubator. Response keys (sensitive to less than $6 \mathrm{~g}$ of force) were mounted directly to the IEE projectors. The stimuli projected were either a white $10-\mathrm{mm}$-diam circle on a red background or a white equilateral triangle $(10-\mathrm{mm}$ sides) on the same red background. Stimulus-reinforcement contingencies were programmed and controlled by BRS electronics solid state modules, and response latencies of the chicks in .1 sec were recorded on four printout counters.

\section{Procedure}

On the day of testing, chicks were removed from their rearing conditions $1 \mathrm{~h}$ before training and isolated in individual, white Plexiglas cylinders $(20 \times 15 \mathrm{~cm})$. These cylinders were placed under fluorescent lights and a masking white noise was delivered through speakers. The purpose of this isolation was to acclimate the social-reared chicks to isolation and all chicks to white noise before conditioning.

Each chick received six training sessions of 24 trials each and then two extinction sessions of 24 trials each. The training procedure used, similar to that described by Brown and Jenkins (1968), was: (1) key-light onset, (2) 16-sec stimulus duration, (3) key-light offset with 8 -sec reinforcement $\left(35^{\circ} \mathrm{C}\right.$ air and light), (4) 5-sec intertrial interval (ITI) with house light on, (5) key-light onset, etc. If the chick pecked the key at any time during the 16-sec stimulus duration, reinforcement was delivered immediately and a new trial was begun after the 5-sec ITI. If the chick failed to respond on any trial, reinforcement was delivered, and $16 \mathrm{sec}$ was recorded for that trial. During acquisition and extinction, the chick was given a "free reinforcement" while being placed in the test box. On the two extinction sessions, no reinforcements were given after the 16-sec stimulus duration; responses during this time were not reinforced, rather the chick was held in the dark chamber for $8 \mathrm{sec}$ before the 5 -sec ITI was initiated. If the chick did not respond on an extinction trial, $16 \mathrm{sec}$ was recorded for that trial and a new trial was begun after the 5-sec ITI. The intersession testing interval was between 15 and $20 \mathrm{~min}$, during which the chicks were returned to their isolation cylinders to minimize experience with interfering stimuli.

\section{RESULTS}

As there were no significant stimulus effects during acquisition training, only rearing conditions will be discussed. There was also no significant difference



BLOCKS OF 6 TRIALS WITHIN EACH SESSION

Figure 1. Mean response latencies of six trial blocks during acquisition and extinction for isolation- and social-reared chicks tested when 3 days old.

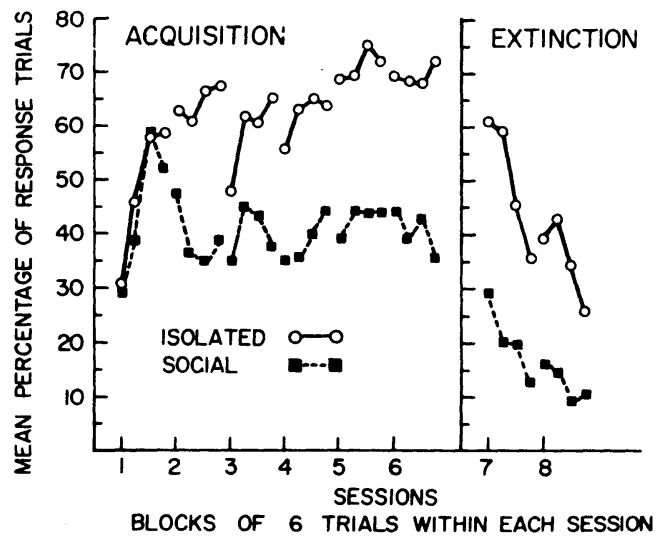

Figure 2. Mean percentage of response trials across six trial blocks during acquisition and extinction for isolationand social-reared chicks tested when 3 days old.

between the social- and isolation-reared chicks in the mean number of stimulus-reinforcement pairings before the first keypeck (social, 23.6 trials; isolation, 25.2 trials). Mean response latencies of six trial blocks for the two rearing groups of 24 chicks each are presented in Figure 1. An analysis of variance with repeated measures was used to determine significance levels.

During acquisition, response latencies of the chicks decreased as the number of training sessions increased, as indicated by a significant session effect $[F(5,230)=$ $5.18, \mathrm{p}<.001]$. Also, the isolation-reared chicks had shorter response latencies than did the social-reared chicks [group effect: $F(1,46)=3.94, p<.05$ ], and this differential responding between the isolated and social chicks increased as training progressed [Group by Session interaction: $F(5,230)=2.75$, p $<.05$ ]

During extinction, the chicks showed a progressive increase in response latencies across the two extinction sessions [session effect: $F(1,46)=20.15$, $p<.001]$. As would be expected from their better terminal acquisition performance, the isolation-reared chicks had shorter response latencies during extinction than did the social-reared chicks [group effect: $\mathrm{F}(1,46)=6.64, \mathrm{p}<.01]$.

Since mean response latencies include both response and nonresponse trials of the chicks, an analysis of variance of the mean percentage of response trials across blocks of six trials for the two groups was also done (Figure 2). Across the two groups, the chicks increased their number of response trials as training progressed, responding on $46 \%$ of the trials during the first acquisition session and on 55\% of the trials on the last acquisition session $[F(5,230)=2.32, p<.05]$. The isolated chicks responded on more trials during acquisition than did the social-reared chicks and showed a significant increase in the number of response trials as training progressed [group effect: $F(1,46)=4.57$, $p<.05$; Group by Session interaction: $F(5,230)=$ $3.63, p<.01]$. That is, the mean percentage of response 
trials for the isolated chicks increased from $48 \%$ to $70 \%$ from Session 1 to 6 , whereas for the social reared chicks the mean percentage of response trials decreased from $45 \%$ to $41 \%$ from the first to the last acquisition session.

During extinction, the chicks showed a significant decrease in their mean percentage of response trials, a decrease of $35 \%$ to $24 \%$ from Extinction Session 1 to 2 , respectively $[\mathrm{F}(1,46)=18.34, \mathrm{p}<.001]$. Also, the isolated chicks responded on more trials $(43 \%)$ during extinction than did the social-reared chicks $(17 \%)$ [group effect: $F(1,46)=9.18, p<.005$ ]

It should be noted that only 2 of the 48 chicks tested did not respond during acquisition training. One of these chicks was social reared and the other isolation reared. Indeed, over $70 \%$ of the chicks responded on at least six consecutive trials during acquisition training, and $83 \%$ of the chicks responded on at least three consecutive trials during acquisition training. An analysis of variance of the percentage of chicks in each rearing group that reached successive criteria of two to six consecutive response trials was also performed, but no significant rearing differences were found in this criterion analysis. From this analysis, however, it was evident that most of the chicks in each group had a significant number of response trials during training.

\section{DISCUSSION}

It is evident that isolation rearing of young Vantress chicks affects their pecking a single stimulus for heat reinforcement. The isolation-reared chicks made more responses and, consequently, had shorter response latencies during acquisition training than did the social-reared chicks. These results are in agreement with those of Brown and Kiely (1974), who found that the prior rearing environment is important in peckrate determination, with isolated chicks pecking more than communal-reared birds when chicks of both rearing groups were tested individually.

Interestingly, the prior rearing conditions did not affect the number of stimulus-reinforcement pairings required to elicit the first keypeck but did affect the maintenance of keypecking once initiated (Figures 1 and 2). Unfortunately, stimulus-reinforcer and response-reinforcer relations were confounded after the first keypeck was elicited; consequently, it cannot be determined whether isolation affected respondent and/or operant conditioning factors (see Wasserman, Hunter, Gutowski,
\& Bader, 1975). But the continuation of stimulus-reinforcement pairings on nonresponse trials in this study apparently had a greater effect on the keypeck performance of the social-reared chicks than on the isolation-reared chicks. In previous studies using similar autoshaping procedures, social-reared chicks given two autoshaping sessions of 24 trials followed by responsereinforced-only trials learned very quickly to keypeck and maintained their discriminative keypeck performance at very high levels (see Zolman et al., 1975).

Brown (1976) has reported that isolation rearing retarded passive avoidance learning in the young chick. In the present autoshaping paradigm, however, isolation rearing facilitated the young chick's keypecking performance. Thus, isolated chicks may be facilitated or retarded in performance by the abnormal rearing procedure, depending upon whether the isolationinduced effects of greater activity and responsiveness are compatible or incompatible with the requirements of the task.

\section{REFERENCES}

Brown, C. P. Passive avoidance in chicks as a function of differential rearing. Animal Learning \& Behavior, 1976. 4. 221-224.

Brown. C. P.. \& Kiely, P. C. The role of early experience and emotionality in social facilitation of pecking in chickens. Animal Behaviour. 1974, 22, 100-109.

Brown, P. L.. \& Jenkins, H. M. Auto-shaping of the pigeon's key peck. Journal of the Experimental Analvsis of Behavior. 1968, 11, 1-8.

Gurton, P. E. Socialization and imprinting in brown leghorn chicks. Animal Behaviour, 1959, 7, 26-34.

Sluckin, W.. \& Salzen, E. A. Imprinting and perceptual learning. Quarterly Journal of Experimental Psychology, 1961. 13. 65-77.

SMith, F. V., \& Bird, M. W. Varying effectiveness of distant intermittent stimuli for the approach response in the domestic chick. Animal Behaviour, 1963, 11, 57-61.

Wasserman, E. A., Hunter, N. B., Gutowski, K. A., \& BADER, S. A. Autoshaping chicks with heat reinforcement: The role of stimulus-reinforcer and response-reinforcer relations. Journal of Experimental Psychology: Animal Behavior Processes. 1975, 104, 158-169.

Zolman, J. F. Discrimination learning in young chicks with heat reinforcement. Psychological Record, 1968, 18, 303-309.

Zolman, J. F., Chandler, S. D., \& Black, D. Visual discrimination learning of the young chick: Key-peck conditioning with heat-light reinforcement. Developmental Psychobiology, 1972, 5, 181-187.

Zolman, J. F., Pursley, D. G., Hall, J. A., \& Sahley, C. L. Form preferences in successive discrimination learning of young chicks. Journal of Comparative and Physiological Psychology, 1975, 89, 1180-1191.

(Received for publication September 1, 1977.) 